\title{
EDUCAÇÃO BÁSICA E AS NOVAS FORMAS DE APRENDER E ENSINAR NA CIBERCULTURA
}

\section{APRESENTAÇÃO}

\author{
Karine Souza Pinheiro ${ }^{1}$ \\ Renata Aquino Ribeiro ${ }^{2}$ \\ Vagna Brito de Lima $^{3}$ \\ Organizadoras
}

O número temático da Revista Docência e Cibercultura (ReDoC) possui o tema "Eclosão dos saberes e fazeres: exercício da docência na educação básica". Para exaltar o movimento que pulsou na educação básica e se intensificou com a cultura digital, com a educação on-line, apresenta-se este dossiê. Nesta revista trazemos as produções científicas, as narrativas, os relatos de educadores com avanços em suas práticas docentes, mas também as contradições, as angústias, os adoecimentos, temas que estavam em todos os contextos desde a escola regular, campesina, indígena, profissional, tempo integral e que passaram a vivenciar um novo repertório, tais como: ensino remoto, ensino híbrido, educação on-line, cibercultura, multiletramentos, didáticas interativas, sala de aula on-line, jogos educacionais, games, formação docente, políticas de inclusão, educação aberta, multimodalidades, inclusão digital.

No contexto da educação remota emergencial da pandemia, despontaram ainda outros obstáculos aos professores, como a leitura da cibercultura, apropriação e recontextualização de interfaces como os mensageiros instantâneos, a exemplo do Whatsapp, para uso institucional e pedagógico. Isso potencializou a complexidade da formação com o uso

\footnotetext{
${ }^{1}$ Pós-doc pela Universidade de Aveiro/PT, Doutora em Ciências da Educação, com especialidade em Tecnologia Educativa (Universidade do Minho/PT), Mestra e Licenciada em Letras/ Universidade Estadual do Ceará - UECE. Professora da Rede Pública do Estado do Ceará - SEDUC, atua na Coordenadoria de Formação Docente e Educação a Distância. Atua nos grupos de pesquisa: GPDOC/UFRRJ, Colearn (Open University/UK), Karine.pinheiro@prof.ce.gov.br.

2 Doutora pela PUC-SP em Educação: Currículo - Tecnologias e autora do Pesquisa Educação.

3 Doutora em Educação (2017) pela Universidade Federal da Paraíba (UFPB), realizou Estágio Científico Avançado de Doutoramento pelo Programa de Doutorado Sanduíche no Exterior (PDSE-CAPES) na Universidade do Minho em Portugal (2016). Mestre em Educação (2012) pela Universidade Federal de Alagoas (UFAL) e professora da educação básica na rede pública estadual do Ceará. Atualmente, é coordenadora estadual da Formação Docente e Educação a Distância da Seduc-CE.
} 


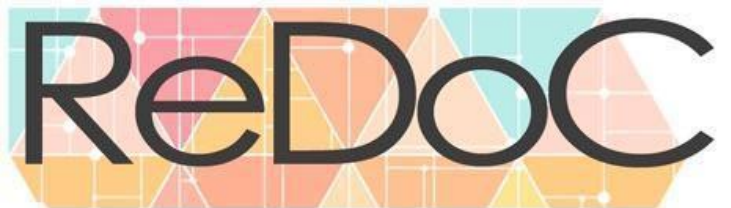

\section{Revista Docência e Cibercultura}

das tecnologias na educação que implicou em quebrar paradigmas, muito além da inserção de docentes e discentes na cultura digital (CAMAS et al., 2013).

Com o avanço da Web 2.0 emergiram mudança culturais, sociais, comunicacionais e, principalmente, educacionais com ações formativas que já aconteciam virtualmente, mas a potência de tudo isso na pandemia, foi a eclosão de jornadas virtuais ${ }^{4}$ passaram a ser o dia a dia dos educadores, desde o ensino superior a educação básica que foram transformados por esse contexto. Ações dessa natureza já eram a tônica da pesquisa de formação como o grupo GPDOC; nessa mesma linha, em 2016, educadores do Ceará debatiam com o mundo seus processos formativos de forma síncrona e assíncrona na educação básica (SOUZA et al., 2016). Estudos como esse nos alertam sobre uma dimensão já insuperável, o domínio da ubiquidade, em que os docentes passaram a ter que dominar a institucionalização on-line de práticas e saberes, substituindo a escola de paredes físicas por grupos de acolhimento e formação on-line.

Por isso, este dossiê é auspicioso ao apresentar o aprendizado de educadorespesquisadores com as mudanças em seus planejamentos, curadorias, avaliações integrando as Tecnologias Digitais de Informação e Comunicação - TDIC. Compreendendo que as TDIC, se utilizadas numa perspectiva interativa, integrativa, em que as/os jovens são protagonistas, autônomas/os, sujeitos que produzem ciência, com uma cidadania digital, pode-se fazer uma educação on-line (SANTOS, 2014). Portanto, essa abordagem nasce de uma concepção freiriana, ao evidenciar que a pesquisa faz parte da definição do ensinar, ou seja, não há ensino sem pesquisa, nem pesquisa sem ensino. Com isso, reforçamos que o saber e o fazer docente da educação básica são saberes científicos. Assim, ao demarcar o fazer científico nesta publicação, apresenta-se "uma possibilidade de reagir às ameaças que têm sido feitas à autonomia dos professores e das escolas" (SAUL, 2017).

Esta edição, volume 5, n.4, procurou retratar alguns desses percursos. Ao apresentá-la, traremos os autores com seus artigos, relatos de experiência, apresentações artísticas culturais. Na seção temática são 11 artigos.

\footnotetext{
${ }^{4}$ Processos formativos on-line que aconteceram de forma síncrona com educadores, cujo resultado encontra-se na obra publicada em 2016, com a participação dos multiplicadores dos Núcleos de Tecnologia Educacional do Estado do Ceará. O livro foi organizado pelas professoras Karine Pinheiro, Renata Aquino Ribeiro, Catarina Tavares Santiago e pelo professor Rozendo Freitas Amorim, da Secretaria da Educação. Disponível em: https://www.seduc.ce.gov.br/wp-content/uploads/sites/37/2021/11/jornadas_virtuais-1.pdf.
} 
No primeiro artigo, as autoras Heloisa Paes de Barros Arruda e Ana Maria Di Grado Hessel refletem os sentimentos e as suas situações indutoras a partir da experiência de cinco professores do Ensino Fundamental da Rede Municipal de São Paulo com as aulas remotas. O estudo com o título "Da angústia à felicidade: caminhos tecnológicos de professores na pandemia" (ARRUDA \& HESSEL, 2021) apresenta a amplitude de sentimentos positivos e negativos relacionados à situação inusitada das aulas remotas. Sentimentos variados foram identificados: ansiedade e angústia pela situação nova e imediata das aulas mediadas pelas TDIC, a felicidade e satisfação dos docentes pela participação dos alunos na aula síncrona, a alegria de alunos, que compreenderam o conteúdo.

No segundo artigo, Adelina Maria Carreiro Moura nos instiga com a questão de como utilizar e potencializar as tecnologias da cultura digital na cibercultura, além de criar experiências de aprendizagem inovadoras e memoráveis para os estudantes. No artigo: “O professor criador de experiências educacionais mediadas por tecnologias digitais na cibercultura" (MOURA, 2021), ela apresenta os resultados de quatro estratégias pedagógicas desenvolvidas com alunos de cinco turmas do Ensino Profissional, por meio de um estudo de caso exploratório, com abordagem mista qualitativa e quantitativa.

Telma Rocha e Cleyton Brandão inovam o debate das fake news com o artigo “Cibercultura, Educação Básica e Pandemia: Plano de Aula sobre as Fake News das Vacinas". Os autores reforçam quanto a educação básica precisa apropriar-se dos processos tecnológicos e comunicacionais da cibercultura. Esse escrito tem o objetivo de apresentar um plano de aula do componente curricular Língua Portuguesa, para $8^{\circ}$ e $9^{\circ}$ ano do Ensino Fundamental II.

A temática do multiletramento esteve presente no artigo de Jeanny Meiry Sombra Silva, Juliana Caetano Neto, Thiago Henrique Valério Pereira e Francielle Aparecida Miquilini Arcega, em que abordam "A integração entre os multiletramentos e a educação midiática: Saberes e práticas docentes na educação básica" (SILVA et al, 2021) . A investigação trata da percepção dos professores ao participarem da experiência didática do Ensino Fundamental, apresentando os sentidos atribuídos por alunos e alunas, ao observar o que a produção deles e delas revela sobre suas aprendizagens. 


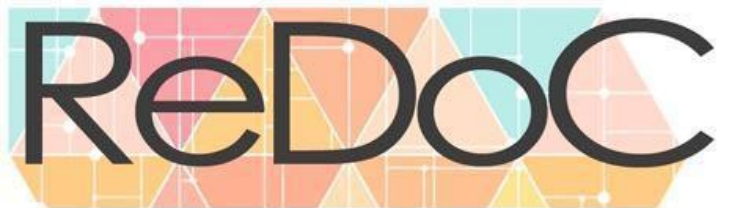

\section{Revista Docência e Cibercultura}

Outro tema muito pesquisado na pandemia encontra-se neste número temático: a abordagem pedagógica denominada Ensino híbrido, com o artigo de Tânia Noemia Rodrigues Braga e Karine Pinheiro de Souza "Do entregador de informação à mediação pedagógica por meio das TDIC na educação híbrida: um estudo de caso de professores da educação básica", em que é tratado um dos princípios educação híbrida com foco na 'personalização do ensino', em que se reconhece como um dos processos da educação on-line, em que os docentes são mediadores por meio do diálogo, na construção do conhecimento mútuo. O objetivo do estudo é apresentar modelos do ensino híbrido para personalização do ensino, promovendo uma aprendizagem centrada no aluno, além de explanar sobre mediação pedagógica por meio de um estudo de caso com professores da educação básica (BRAGA \& SOUZA, 2021).

No sexto artigo, a experiência do Ensino Fundamental de Aurinete Alves Nogueira, Francisca Regiane Sabino de Sousa, Franscisca Geny Lustosa e Aleandra de Paiva Nepomuceno traz uma pesquisa cartográfica com narrativas das professoras-pesquisadorasautoras, registros de diários de campo, planejamentos de aulas no âmbito do trabalho remoto, consulta a normativas, pareceres e portarias designando o ensino remoto nacional e da rede municipal de Fortaleza. O estudo aponta para a emergência de novos saberes-fazeres, além dos desafios da docência, no artigo intitulado "Um novo tempo, apesar dos perigos: atuação docente na educação básica no contexto da cibercultura - a voz das educadoras!” (NOGUEIRA et al, 2021).

Outra experiência relatada da educação básica é o estudo de Ana Luiza Zappe Desordi Flôres, Quelen Colman Espíndola Lima, Cadidja Coutinho, Raquel Ruppenthal e Mara Regina Bonini Marzari sobre o Google Classroom como ambiente para a formação continuada de professores: desafios e possibilidades. O artigo avalia o desenvolvimento do curso "Sequências didáticas para promover o Letramento Científico", as possibilidades e os desafios do uso da plataforma (FLORES et al, 2021).

Com um título que ressalta os desafios da temporalidade do período pandêmico, o artigo "O 20 do XXI: práticas de ensino desafiadoras em um tempo de tormentas", de Rodrigo dos Reis Nunes e Josiane Bispo Cruz Lima. O trabalho (NUNES \& LIMA, 2021) versou acerca das práticas de ensino desafiadoras frente às instabilidades do século XXI e, de forma mais específica, no ano de 2020, o estudo de caso foi com docentes da rede pública e privada de 


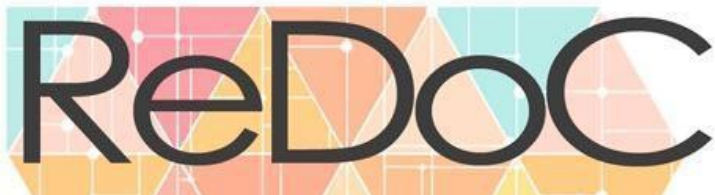

\section{Revista Docência e Cibercultura}

ensino da cidade de Tapiramutá - Bahia sobre a realidade de trabalho frente à pandemia e como eles têm lidado com as tecnologias digitais da informação e da comunicação (TDIC).

No nono artigo a experiência lúdica e o uso dos jogos na educação foi a tônica de Juliana Caetano Nêto e Patrick de Menezes em: “Games como máquinas de aprendizagem: um relato de experiência com o uso dos games Assassin's Creed e Civilization VI na disciplina de História". O texto (CAETANO NETO \& MENEZES, 2021) reflete sobre o potencial pedagógico do uso de games comerciais na educação básica em vista das potencialidades desses ambientes imersivos como máquinas de aprendizagem. $\mathrm{O}$ estudo de caso investiga o uso dos dois games comerciais, em uma escola privada bilíngue em São Paulo, por fim reforça que o uso de jogos na educação propicia o desenvolvimento cognitivo e emocional, torna-se um forte aliado na escolha de novas metodologias para o ensino.

No décimo artigo, uma tradução resumida de autores de 5 países: "Educação aberta como mudança de jogo: história da pandemia" por Renata Aquino Ribeiro (2021), traduzido do original de autoria de Magdalena Biernat, Karolina Szczepaniak, Maria Mirecka, Alek Tarkowski, Nikolaos Panagiotou, Chrysoula Lazou, Matteo Uggeri, Virginia Rodés, Patricia Díaz Charquero, Kamil Śliwowski, Tomasz Piątek e Renata Aquino Ribeiro.

No último artigo da seção, o texto de Adelson Pereira de Sousa e Verônica de Oliveira Magalhães, apresentam: " Representações Sociais da Docência no Ensino fundamental II: percepção do professor e identidade docente" (DE SOUZA \& MAGALHÃES, 2021). A pesquisa apresenta o contexto político econômico-social, em um momento do avanço da direita brasileira no plano do parlamento e da conquista do executivo federal. A polarização que marcou as eleições presidenciais de 2018 fez surgir uma espécie de "criminalização" de alguns setores sociais ou categorias profissionais por parte das novas forças políticas que surgiram das urnas, tais como artistas, jornalistas e professores. Em meio a essa onda conservadora de desqualificação do professor e da educação escolar, algumas reflexões sobre as políticas públicas educacionais devem ser retomadas, tais como: o sucateamento da escola de educação básica, a precariedade da formação docente e a política de valorização das atividades ligadas ao magistério. Este ensaio objetiva analisar como o professor do $6^{\circ}$ ano do Ensino Fundamental se percebe enquanto sujeito nesse momento de polarização ideológica.

Na seção dos Relatos de Experiência encontram-se três trabalhos sobre essas 


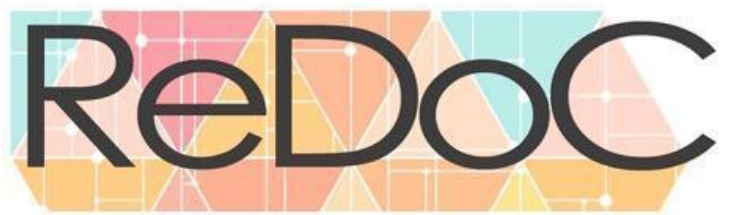

\section{Revista Docência e Cibercultura}

narrativas e experiências docentes. A primeira delas é sobre o uso das TDIC por alunas/os chamadas/os de nativas/os digitais em Escola Pública Estadual de Ensino Médio em RecifePE, as/os autoras/es: Claudemir Jeremias de Lima, Gilberto Amado de Azevedo Cysneiros Filho, Neiton Carvalho da Silva e Elidiene Gomes de Oliveira Lima. Essa pesquisa visa investigar as dificuldades dos estudantes na utilização dos recursos tecnológicos, em uma escola da rede pública da região metropolitana do Recife (DE LIMA et al, 2021).

No texto de Sebastião da Silva Vieira, Roberta Barros de Oliveira Nascimento, Cabral Guerra Gerusa, Josimar Alves Alves e Rosangela Renovato, um estudo sobre estratégias pedagógicas em tempos de pandemia, como proposta de comunicação em aulas remotas por meio do WhatsApp com estudantes do Ensino Fundamental I, com o título "Educação em tempos pandêmicos: o uso do aplicativo WhatsApp como proposta de comunicação em aulas remotas" (VIEIRA et al, 2021).

Por fim, a narrativa com o título "Versos e Reversos de uma Gestora Escolar em Tempos de Ensino Remoto" (MUNIZ, 2021), em que apresenta uma pesquisa autobiográfica sobre as dificuldades, os desafios e as superações, envolvendo os diferentes processos que são realidades na educação como a avaliação, o acompanhamento pedagógico e o desenvolvimento de projetos que acontecem no cotidiano escolar, e como tudo isso tornou-se possível acontecer fora dos muros da escola no período pandêmico.

Uma inovação nesta seção é o forte crescimento das produções artísticas, literárias e culturais em que apresenta-se linguagem da esquete on-line "Educação além da distância: compartilhando experiências das aulas virtuais de teatro no IFCE" que também nos instiga a repensar nossas aulas virtuais, diante da reflexão dos autores José Tomaz de Aquino Júnior, Maria Jaene Aguiar Pinho, Rayssa Torres Dias vivencia-se as aulas remotas seus desafios e conquistas (AQUINO JÚNIOR, PINHO E DIAS, 2021)

A segunda produção que emergi com sua multimodalidade virtual é "O Andarilhar pandêmico em foto-poéticas rizomáticas" de Tiago Amaral Sales, Fernanda Monteiro Rigue com os seus registros fotográficos e, posteriormente, experimentações visuais com estas fotos. Sales e Ringue (2021) criam narrativas rizomáticas ao andarilhar pelos nossos territórios de 


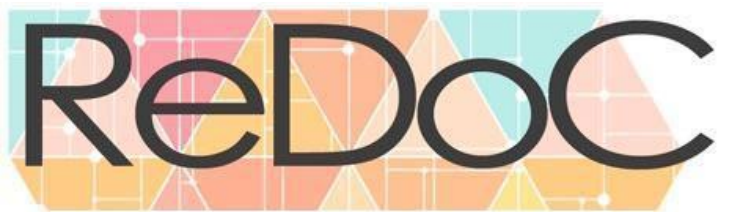

\section{Revista Docência e Cibercultura}

pesquisa-vida, criando paisagens outras, em experimentações, em que foram contaminados pela base teórica da Filosofia da Diferença.

Uma inovação no fim desta seção é o forte crescimento da criatividade latente nos jovens com as produções artísticas, em que se evidência na capa deste dossiê a seleção de algumas produções de "Rir é um bom remédio e pode ajudar a vencer a Covid-19: adolescentes e jovens utilizam o humor para conscientizar territórios vulneráveis"5, por Mônica Mandaji, Guilherme Freitas, Kamyla Amorim, Pedro Amorim e Vanessa Reis. A produção é resultado do trabalho de 50 jovens de cinco territórios brasileiros, que foram formados para desenvolver e difundir mensagens em suas comunidades, criando, assim, um caminho para o combate à Covid-19 ( MANDAJI et al, 2021).

Por fim, nossa entrevista destaca “ $\mathrm{O}$ exercício da docência na educação básica no contexto da cibercultura" em que Vagna Brito de Lima, dialoga com dois profissionais com efetiva atuação na educação básica, são eles: Rogers Vasconcelos Mendes e César Augusto Amaral. Os entrevistados situados em diferentes esferas, identificam as percepções sobre o exercício da docência no contexto da cibercultura.

São esses 18 trabalhos que compõem este número temático de edição especial da ReDoC em que eclodiram saberes e fazeres para inspirar o cotidiano docente, que vem superando as dificuldades do momento pandêmico e que cria formas de emanar soluções, superações, colaborações em rede que ressoam em uma nova forma de aprender e ensinar. Com isso, educadores gritam a ciência da educação básica no/para o mundo com produções originais elaboradas com a comunidade científica nacional e internacional, com relatos de experiências, artigos, vídeo-pesquisa, produções artísticas culturais deixando seus rastros de identidade e diferença na Revista Docência e Cibercultura.

Tenham uma excelente leitura!

\footnotetext{
${ }^{5}$ Em evidência ao projeto a capa deste número temático traz ilustrações do projeto da Fiocruz, Sesc e IK4T na rede Instagram, o \#Ficaemcasacomhumor.
} 


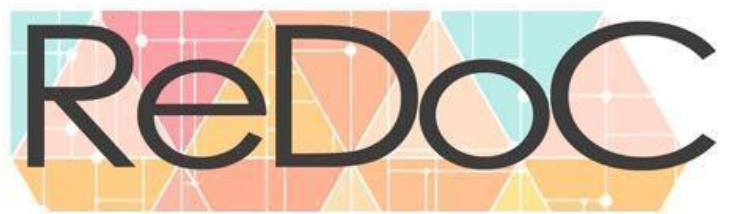

Revista Docência e Cibercultura

\section{REFERÊNCIAS}

AQUINO JÚNIOR, José Tomaz de; PINHO, Maria Jaene Aguiar; DIAS, Rayssa Torres.

Esquete online educação além da distância: compartilhando experiências das aulas virtuais de teatro no IFCE. Revista Docência e Cibercultura, v. 5, n. 4, edição especial, 2021, p. 303305. DOI: https://doi.org/10.12957/redoc.2021.61779

ARRUDA, Heloisa Paes de Barros; HESSEL, Ana Maria Di Grado. Da angústia à felicidade: caminhos tecnológicos de professores na pandemia. Revista Docência e Cibercultura, v. 5, n. 4, edição especial, 2021, p. 24-50. DOI: https://doi.org/10.12957/redoc.2021.60048

BRAGA, Tânia Noemia Rodrigues; SOUZA, Karine Pinheiro. Do entregador de informação a mediação pedagógica por meio das TDIC na educação híbrida: um estudo de caso de professores da educação básica. Revista Docência e Cibercultura, v. 5, n. 4, edição especial, 2021, p. 121-139. DOI: https://doi.org/10.12957/redoc.2021.57472

CAMAS, N. MANDAJI, M. MENGALLI, N. RIBEIRO, R. Professor e cultura digital: reflexão teórica acerca dos novos desafios na ação formadora para nosso século. Revista Reflexão e Ação. v. 21, n. 2, 2013. P. 179 - 198. Disponível em:

http://online.unisc.br/seer/index.php/reflex/article/view/3834. Acesso em: 15 set. 2021.

FLÔRES, Ana Luiza Zappe Desordi; LIMA, Quelen Colman Espíndola; COUTINHO, Cadidja; RUPPENTHAL, Raquel; MARZARI, Mara Regina Bonini. Google classroom como ambiente para a formação continuada de professores: desafios e possibilidades. Revista Docência e Cibercultura, v. 5, n. 4, edição especial, 2021, p. 160-172. DOI: https://doi.org/10.12957/redoc.2021.57463

LIMA, Claudemir Jeremias de; CYSNEIROS FILHO, Gilberto Amado de Azevedo; SILVA, Neiton Carvalho da; LIMA, Elidiene gomes de oliveira. Relato de Experiência do uso das TDIC por alunos chamados de nativos digitais em Escola Pública Estadual de Ensino Médio em Recife-PE. Revista Docência e Cibercultura, v. 5, n. 4, edição especial, 2021, p. 258272. DOI: https://doi.org/10.12957/redoc.2021.59815

LIMA, Vagna Brito de. O exercício da docência na educação básica no contexto da cibercultura. Revista Docência e Cibercultura, v. 5, n. 4, edição especial, 2021, p. 334-343. DOI: https://doi.org/10.12957/redoc.2021.64181

MANDAJI, Mônica; GRAD, Guilherme Freitas; AMORIM, Kamyla; AMORIM, Pedro; REIS, Vanessa. "Rir é um bom remédio e pode ajudar a vencer a Covid-19" Adolescentes e jovens utilizam o humor para conscientizar territórios vulneráveis. Revista Docência e Cibercultura, v. 5, n. 4, edição especial, 2021, p. 324-333. DOI:

https://doi.org/10.12957/redoc.2021.62226

MOURA, Adelina Maria Carreiro. O professor criador de experiências educacionais mediadas por tecnologias digitais na cibercultura. Revista Docência e Cibercultura, v. 5, n. 


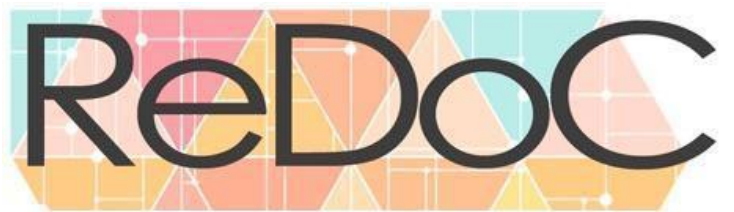

\section{Revista Docência e Cibercultura}

4, edição especial, 2021, p. 51-73. DOI: https://doi.org/10.12957/redoc.2021.60475

MUNIZ, Joseane Lima. Versos e reversos de uma gestora escolar em tempos de ensino remoto. Revista Docência e Cibercultura, v. 5, n. 4, edição especial, 2021, p. 286-302. DOI: https://doi.org/10.12957/redoc.2021.59534

NÊTO, Juliana Caetano; MENEZES, Patrick de. Games como máquinas de aprendizagem: um relato de experiência com o uso dos games Assassin's Creed e Civilization VI na disciplina de História. Revista Docência e Cibercultura, v. 5, n. 4, edição especial, 2021, p. 191-215. DOI: https://doi.org/10.12957/redoc.2021.58461

NOGUEIRA, Aurinete Alves; SOUSA, Francisca Regiane Sabino de; LUSTOSA, Francisca Geny; NEPOMUCENO, Aleandra de Paiva. Um novo tempo, apesar dos perigos: atuação docente na educação básica no contexto da cibercultura - a voz das educadoras! Revista Docência e Cibercultura, v. 5, n. 4, edição especial, 2021, p. 140-159. DOI: https://doi.org/10.12957/redoc.2021.60443

NUNES, Rodrigo dos Reis; LIMA, Josiane Bispo Cruz. O 20 do XXI: práticas de ensino desafiadoras em um tempo de tormentas. Revista Docência e Cibercultura, v. 5, n. 4, edição especial, 2021, p. 173-190. DOI: https://doi.org/10.12957/redoc.2021.56216

RIBEIRO, Renata Aquino. Educação Aberta como mudança de jogo: histórias da pandemia. Revista Docência e Cibercultura, v. 5, n. 4, edição especial, 2021, p. 216-240. DOI: https://doi.org/10.12957/redoc.2021.62224

ROCHA, Telma; BRANDÃO Cleyton. Cibercultura, educação básica e pandemia: plano de aula sobre as fake news das vacinas. Revista Docência e Cibercultura, v. 5, n. 4, edição especial, 2021, p. 74-96. DOI: https://doi.org/10.12957/redoc.2021.60979

SALES, Tiago Amaral; RIGUE, Fernanda Monteiro. Andarilhar pandêmico em foto-poéticas rizomáticas. Revista Docência e Cibercultura, v. 5, n. 4, edição especial, 2021, p. 306-323. DOI: https://doi.org/10.12957/redoc.2021.61833

SANTOS, E. \& SILVA, M. O desenho didático interativo na educação online. Revista Iberoamericana de Educación, v. 49, p. 267-287, 2009.

SAUL, Ana Maria; SAUL, Alexandre. O saber/fazer docente no contexto do pensamento de Paulo Freire: contribuições para a Didática. Cadernos de Pesquisa, v. 24, n. 1, p. 1-14, 2017. Disponível em: http://www.periodicoseletronicos.ufma.br/index.php/cadernosdepesquisa/article/view/17579. Acesso em: 15 set. 2021.

SILVA, Jeanny Meiry Sombra; NETO, Juliana Caetano; PEREIRA, Thiago Henrique Valério; ARCEGA, Francielle Aparecida Miquilini. Integração entre os multiletramentos e a educação midiática: saberes e práticas docentes na educação básica. Revista Docência e Cibercultura, v. 5, n. 4, edição especial, 2021, p. 97-120. DOI:

https://doi.org/10.12957/redoc.2021.59471 


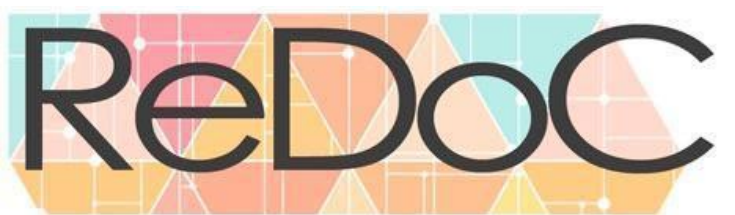

\section{Revista Docência e Cibercultura}

SOUSA, Adelson Pereira de Sousa; MAGALHÃES, Verônica de Oliveira. Representações sociais da docência no Ensino Fundamental II: percepção do professor e identidade docente. Revista Docência e Cibercultura, v. 5, n. 4, edição especial, 2021, p. 241-257. DOI: https://doi.org/10.12957/redoc.2021.55113

SOUZA, K. P., RIBEIRO, R. A., SANTIAGO C. T., AMORIM, R. F. (Orgs.). Jornadas Virtuais: Vivências e Práticas das Tecnologias Educativas. Secretaria de Educação do Estado do Ceará SEDUC; Fortaleza: Instituto Brasileiro de Informação em Ciência e Tecnologia - IBICT, 2016. Disponível em: https://www.academia.edu/34696942/Jornadas_Virtuais_Viv\%C3\%AAncias_e_Pr\%C3\%A1ticas_das _Tecnologias_Educativas. Acesso em: 15 set. 2021.

SOUZA, Karine Pinheiro; AQUINO, Renata; LIMA, Vagna. Docência e cibercultura na educação básica. Revista Docência e Cibercultura, v. 5, n. 4, edição especial, 2021, p. 1423. DOI: https://doi.org/10.12957/redoc.2021.63834

VIEIRA, Sebastiao da Silva; NASCIMENTO, Roberta Barros de Oliveira; GERUSA, Cabral Guerra; ALVES, Josimar; RENOVATO, Rosangela. Educação em tempos pandêmicos: o uso do aplicativo WhatsApp como proposta de comunicação em aulas remotas. Revista Docência e Cibercultura, v. 5, n. 4, edição especial, 2021, p. 273-285. DOI: https://doi.org/10.12957/redoc.2021.53827

Este é um artigo de acesso aberto distribuído sob os termos da Licença Creative Commons Atribuição Não Comercial-Compartilha Igual (CC BY-NC- 4.0), que permite uso, distribuição e reprodução para fins não comerciais, com a citação dos autores e da fonte original e sob a mesma licença. 